\title{
Urban Use and Urban Form: Alexanderstrasse, Berlin
}

\author{
LESLIE FORSYTH and ANDREA HAASE \\ Rheinisch-Westfalische Technische Hochschule - Aachen \\ Germany
}

\section{INTRODUCTION}

This paper attempts to illustrate the suitability of specific urban forms for particular planning objectives within a given urban context. Proposals for a reurbanisation project in Berlin are discussed. The proposals were prepared by students during 1992-1993 in conjunction with a study to improve rail transport and areas around railway and underground stations by SNV Studiengesellschaft Verkehr mbH. Berlin. The designs seek to interpret the existing planning aims for the area around Alexanderstrasse, south of Alexanderplatz from the City of Berlin and from the District Berlin-Mitte. An evaluation of the range of proposals points to four basic type solutions for the urban structure. The suitability of particular forms for specific aims is noted as well as the structure which appears to offer the greatest potential to reconcile at least some of the conflicting aims for the area.

\section{CONTEXT}

In Berlin in 1992 there were a wide range of town planning issues to be addressed. These included the city's metropolitan function, its role as a capital and seat of government, the possibility of hosting the Olympic Games, the need for more service and office floorspace, the shortage of housing, the integration of the east and west sectors of the city, the role of the city itself within the region and the development of public and private transport.

One of the strategies which was adopted as part of the response was to strengthen and develop city centre functions in two important locations around $\mathrm{Ku}-\mathrm{Damm}$ and Breitscheidtplatz in the western sector and in the area around Alexanderplatz in the east. The western location was already functioning, however, the eastern focus did not have the diversity of urban forms and functions necessary to perform this role. This meant the development of a new centre able to provide space for living, working, communication and consumption within a new urban structure. In 1993 Alexanderplatz was the subject of an international design competition. The site with which this paper deals stretches from the south east edge of Alexanderplatz to the River Spree.

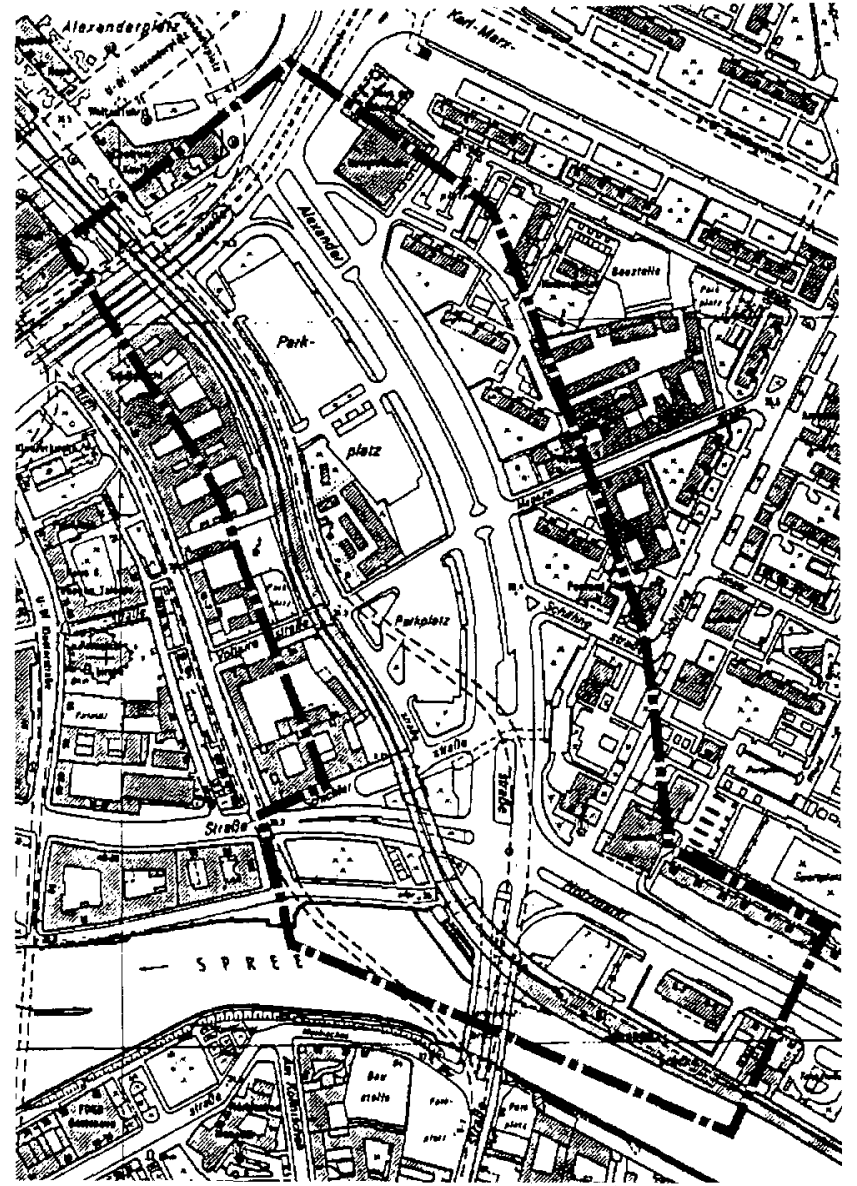

Fig. I. Site plan

\section{SITE APPRAISAL}

Four districts of Berlin converge around Alexanderplatz: the former Marienviertel of old Berlin, the Spandauer Vorstadt, Prenzlauer Berg and the former Strahlauer Vorstadt, which has been drastically altered through the building of KarlMarx-Allee and its surrounding housing. The banana shaped site between Alexanderplatz and Jannowitzbrücke is where two different spatial concepts collide with one another separated by the former city wall, now the railway viaduct. The site encompasses the area south east from Alexanderplatz 
along Alexanderstrasse, bounded by the railway viaduct to the west, a housing estate consisting of prefabricated blocks of flats to the east and Jannowitzbrücke and the River Spree to the south.

An analysis of the site was carried out by breaking it into its five sub areas: the two nodes at either end, Alexanderplatz and Jannowitzbrücke, and the three north south strips, west of the railway, east of Alexanderstrasse and the area which lies between them and connects the two nodes. Then the categories of use, circulation, spatial organisation and environment were used to examine the qualities of each sub-area.

The existing uses are dominated by residential and associated facilities with less extensive business and service zones. There is a lack of leisure and recreation facilities. Alexanderplatz with its underground and S-Bahn stations and the S-Bahn station at Jannowitzbrücke plus the numerous bus and tram routes ensure that this is one of the best connected public transport locations in the city. The equally good facilities for the private car bring with them the disadvantages of over-dimensioned roads and car parks. Spatially, the railway viaduct and the restricted views to the old city provide the few elements of quality. The dominant roadways and parking areas leave the site open to the south and east. At the time of the appraisal the level of exhaust fumes and noise from the traffic was very high. Combined with the extremely high level of sealed surface areas and the very poor level of the network of green areas the environmental quality of the site appeared poor.

\section{PLANNING GUIDELINES}

In 1992 there were no legally binding plans for the area. The basis for guidance from the city lay in the "Basis for Landuse Planning"'(Grundlagen für die Flächennutzungsplanung 1992) and for the District Berlin-Mitte in the document "Area Development Planning" (Bereichsentwicklungsplanung Bezirk-Mitte 1991). A review of both documents revealed four main objectives which might be used as criteria against which any design proposals could be assessed:

- The development of a new eastern city centre around Alexanderplatz. This means that Alexanderstrasse should develop at least in part as an urban core. A specific increase in density is expected and normal central and peripheral-central uses should be represented.

- An improvement in the environmental conditions and network of green spaces. The focus here should be on reducing individual traffic although unsealing surface areas and providing new green and recreation space is as important.

- Protection of the existing employment and residential opportunities as well as the creation of new employment and at least $20 \%$ residential accommodation in the new development.

- An improvement in the spatial quality. Alexanderplatz and its surroundings are the meeting point for four city districts and the site itself lies between different types of built form and use structure. The site should reflect this position spatially and in its built form.

\section{TYPE SOLUTIONS}

Twenty three design proposals were prepared by students during the period October 1992 to June 1993. These were then grouped into type solutions according to their spatial organisation, building structure, use patterns, circulations systems and green structure. Then the type solutions were compared in relation to the main points arising from the planning guidelines and site analysis. Four different spatial concepts can be determined :

- A block structure with edges to Alexanderstrasse, Dirckenstrasse and along the east west connecting streets.

- An edge to the railway viaduct and another to Alexanderstrasse with free standing individual buildings or green spaces in between.

- An edge to Alexanderstrasse with a more open court or row development towards the railway.

- An edge to the railway viaduct opening out to a park in front of the housing estate in the east.

\section{Block structure}

The proposals under this concept represent the solutions with the highest density. The form of the designs is dominated for the most part by sequences of between three and six blocks on a north south axis, which build an island between the viaduct and the housing. Openings in the sequences give an indication of the degree of permeability from the housing estate. A mix of uses is proposed with shopping parallel to the railway viaduct and in Alexanderstrasse or in a north-south passage. Offices are located over the shops with residential uses in the upper floors. In one or two proposals residential use is the main focus with a consequential increase in the proportion of floor space allocated for that purpose. The circulation systems consist of a north south spine with the east west connections having lesser importance. Alexanderstrasse is reduced in width in all the design proposals. Public open space is either concentrated at the junction of Voltairestrasse, Magazinstrasse and Alexanderstrasse or on the bank of the river. The areas inside the blocks are given over to private open space.

\section{An edge on both sides}

This idea has much in common with that of the block structure. The buildings along Alexanderstrasse and Dirckenstrasse form either an edge which is broken at points or the whole edge is made up of individual buildings. The area between these edges is very sparsely developed or left as open space. The uses correspond with the built form. At the edges there is shopping on the ground floor with offices and then residential uses on the upper floors. The space between the edges is used for leisure or as green space. The building parallel to the railway viaduct finds a response in the 


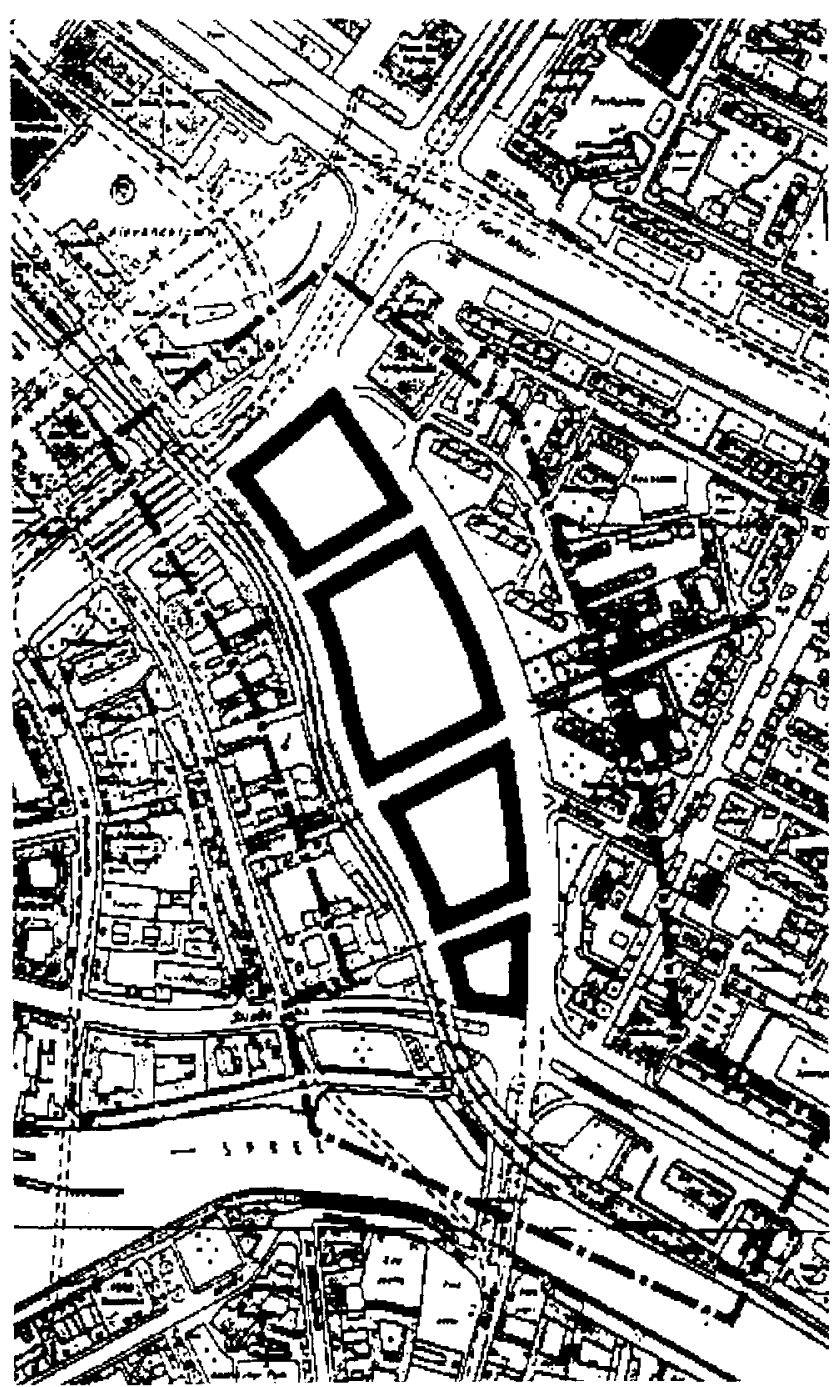

Fig. 2. Block structure

re-use of the viaduct for shopping and service industry. Circulation consists of the two north-south streets with streets of lesser importance running east west. A large area of public open space is concentrated between the two edges.

\section{Edge to Alexanderstrasse}

This type solution tends to create a boundary between the existing housing and the new development through emphasising the built form along Alexanderstrasse, either as a continuous facade or as an interplay between buildings and openings. Behind the main facade lies a sequence of courtyards and rows of buildings at right angles to the street. The mix of uses provides shops and offices along Alexanderstrasse with service, small trades and residential uses behind the main facade. The main circulation takes place on Alexanderstrasse with restricted use of Dirckenstrasse. The courtyards are accesed using culs-de-sac. Open and green space is to be found for the most part at the rear, in the courtyards or between the rows of buildings and is primarily private.

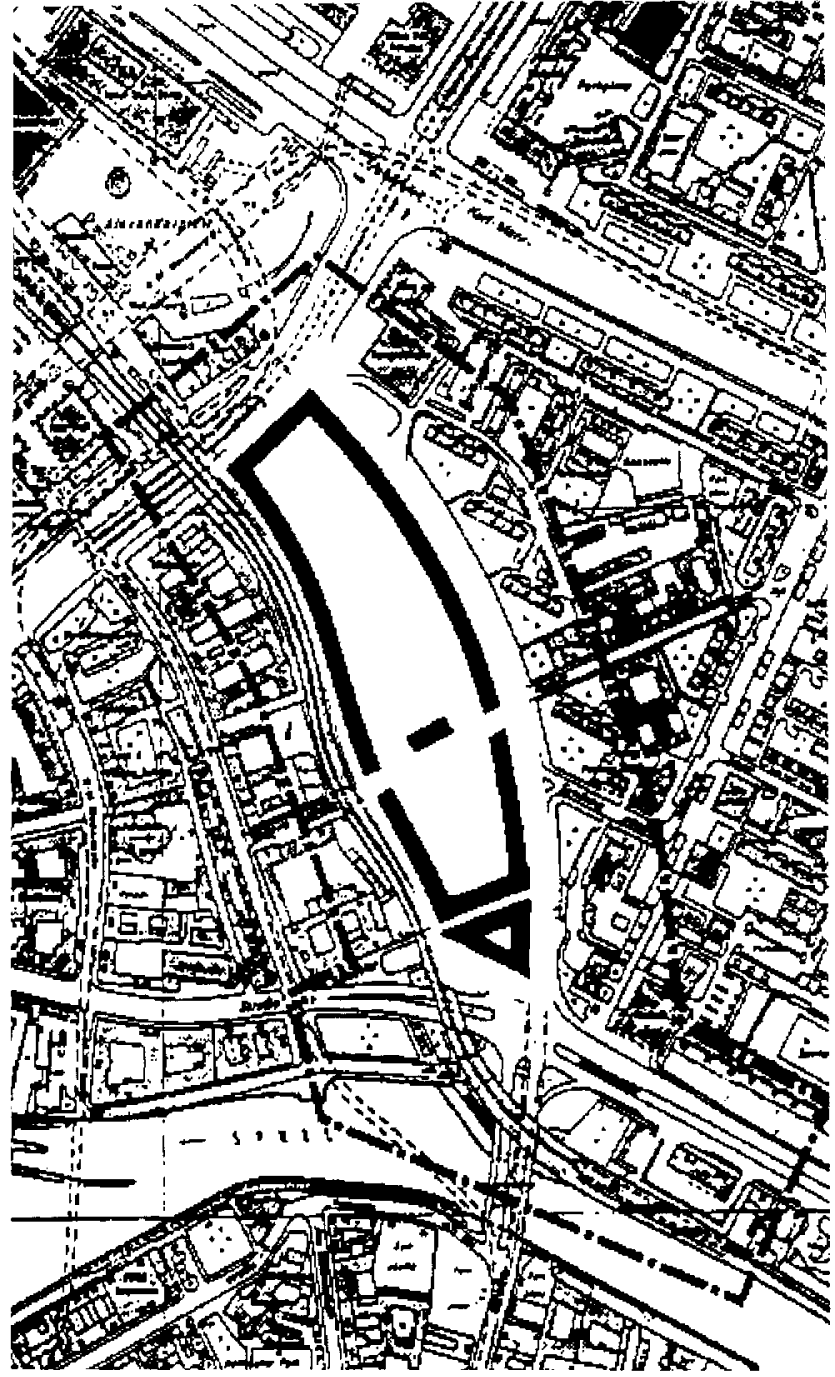

Fig. 3. Edge to both sides

\section{Edge to the railway viaduct}

The main idea behind this type solution is the introduction of green space into the city. The proposals include a large park which acts as a link between the housing estate and the new development as well as between Alexanderplatz and the river. On the western edge there is a terrace parallel to the railway. The built form between the terrace and the park acts either as a connecting or separating structure. The separation shows itself as a straight edge, while the attempts at linking rely on fingers of green and buildings. Dirckenstrasse becomes the main shopping street with offices in the upper floors. In the area behind the facade there are suggestions for small industrial courtyards, local administration or simply residential use. Vehicular circulation is concentrated along one north south street with Alexanderstrasse restricted to occasional or only pedestrian use. The inner areas are accessed from Dirckenstrasse using culs-de-sac. The public open spaces and structure of green areas are generous, connecting the river to Alexanderplatz along a green finger in the urban structure. 


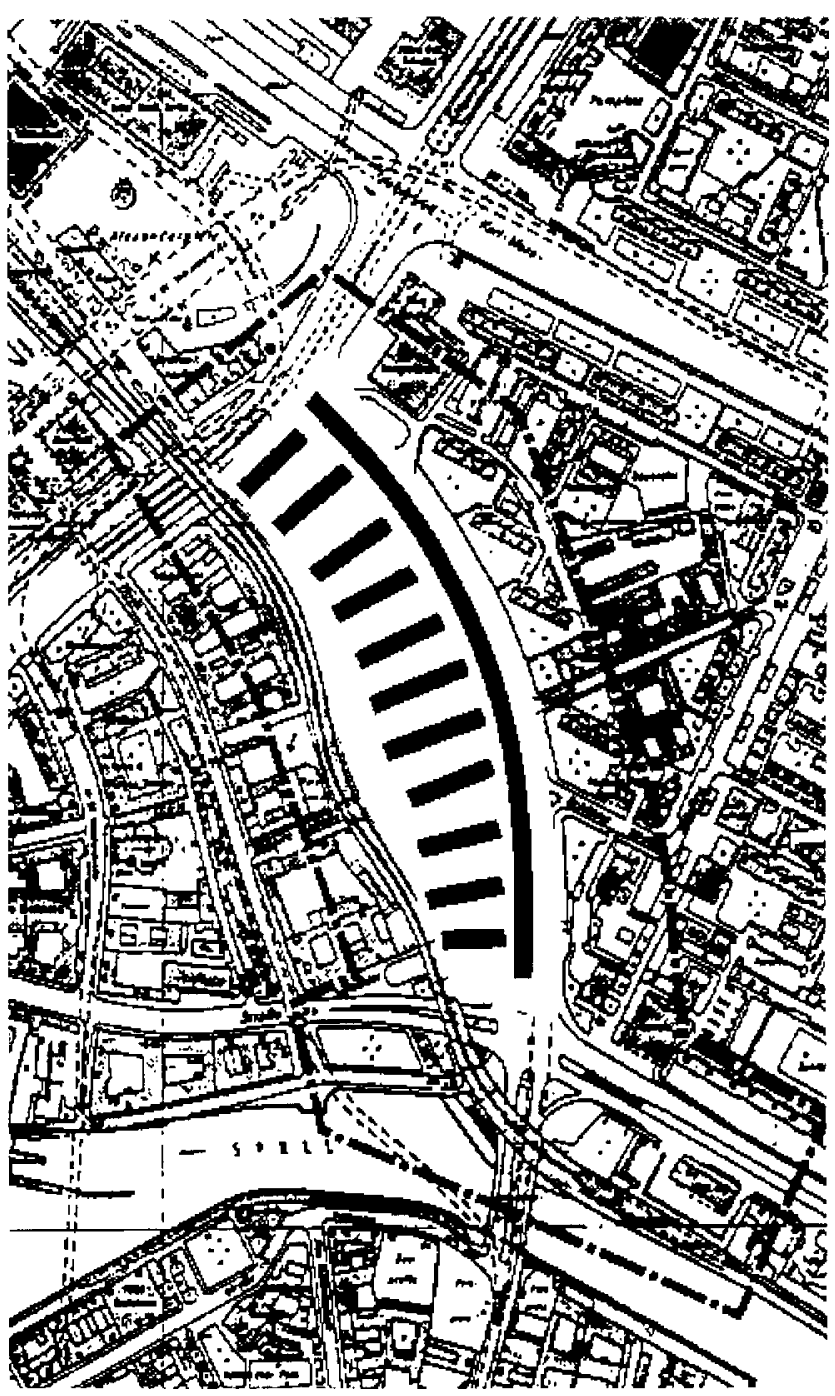

Fig. 4. Edge to Alexanderstrasse

\section{EVALUATION}

All of the design proposals took note of the criteria outlined in the Planning Guidelines and arising from the site appraisal but the emphasis given to particular aspects depends greatly on which type solution the proposal follows.

The block structure lends itself particularly well to the concept of a new high density centre. It is suitable for the required mix of uses and expected levels and types of investment. Whether this structure can satisfy the environmental demands remains unclear. Traffic reduction and calming measures are in evidence but the amount of surface area which remains unsealed is very small. Green space is restricted to the river bank, the streets or the inner areas of blocks. The spatial qualities which result tend to be an extension of the pattern of historic Berlin rather than a link or transition between diferent areas.

The solution with two edges has similar qualities to the block structure. It provides a suitable form for the extension of the new centre along Alexanderstrasse and is flexible enough to offer an appropriate mix of uses. In this solution

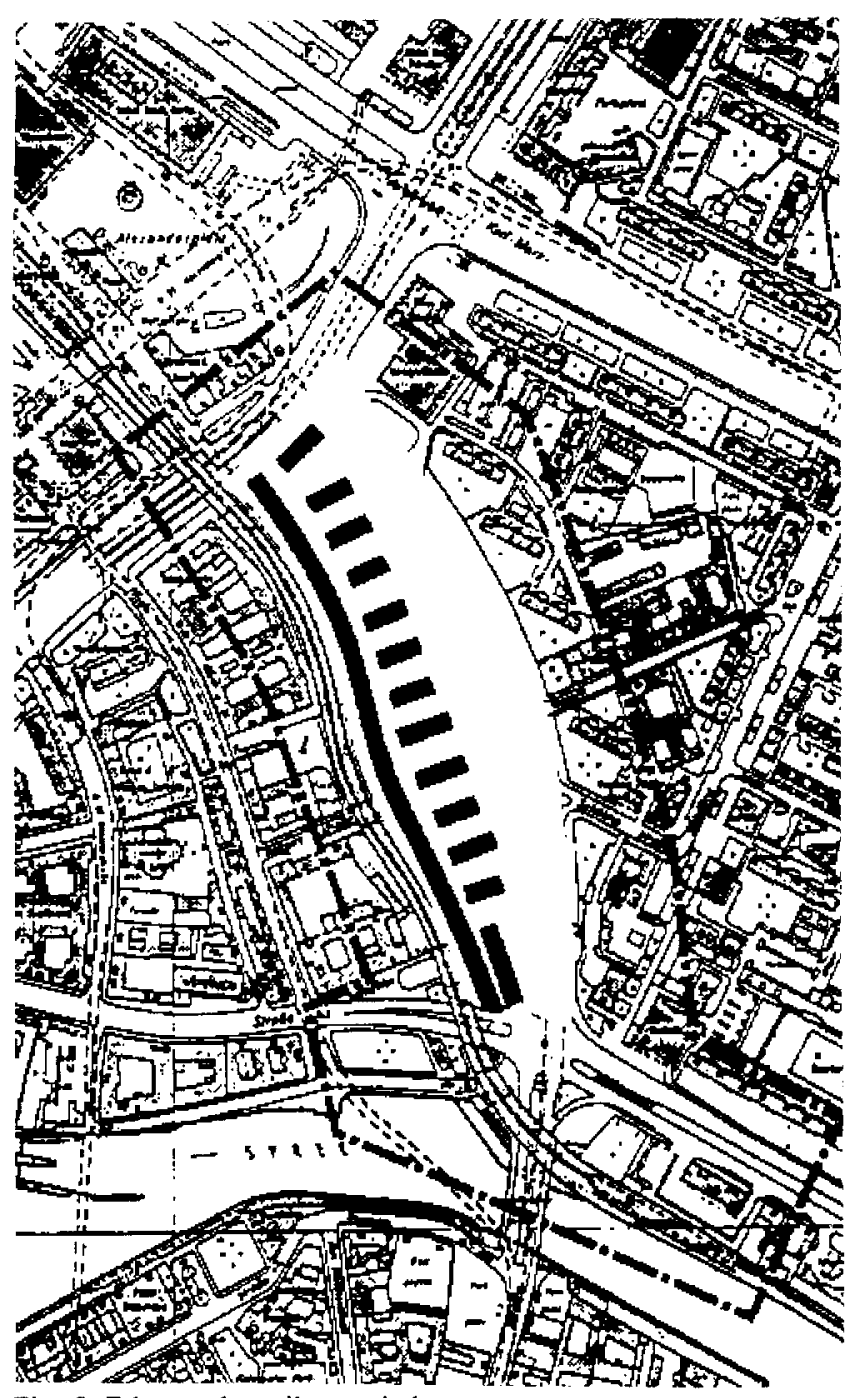

Fig. 5. Edge to the railway viaduct

the unsealed surface area and landscaped open space extend from north to south over the whole length of the new development. This also offers the opportunity to reduce the current deficit in recreation and leisure facilities. The spatial form of the development reflects neither the historical city nor the free standing blocks of the housing estate, but acts as a transition element both in a north-south and east-west direction.

In the proposals with an edge to Alexanderstrasse the density of the development is concentrated along this facade. The street is conceived as the axis between the river and Alexanderplatz with less important uses in the back courts. The structure of open spaces and green areas is almost always private apart from on the street. Since the inner areas are built up the extent of the unsealed surface area is limited. The main facade to the street with the back areas to the viaduct represents the typical structure for a situation next to the railway allowing the opportunity for small trades and services to exist. The built form separates itself from the housing estate through the handling of Alexanderstrasse and 
links to the railway viaduct rather than through to the historical structure.

Proposals which include an edge to the railway viaduct and a park between the existing and the new development could encounter problems with density, It is not certain whether they could achieve the high-density requirements of the planning guidelines or the structure of a city centre without significant high rise developments at selected locations. On the other hand this type solution contains advantages for the environmental quality. By removing traffic from Alexanderstrasse and creating a park, the connection of green spaces as well as leisure and recreation opportunities are greatly improved. Similarly, extensive areas of ground can be unsealed. The spatial structure separates old and new by introducing a green wedge. The main axis to Alexanderplatz disappears and the greatly reduced north south traffic uses Dirckenstrasse.

\section{CONCLUSION}

From the evaluation it is evident that the diverse objectives for the area provide little opportunity to reach a solution which would satisfy fully all of the stated objectives. However, a compromise solution which satisfies most of the aims is available. The type solution which appears to offer the most chance of a constructive compromise is that with an edge to both sides and with a large free area in between. It could be densely enough developed to satisfy market demands adjacent to a city core along with an appropriate mix of uses to facilitate the residential requirements and employment potential. At the same time the areas between the edges of the development could go some way to satisfying the environmental objectives of improved green linkages to the river, a high percentage of unsealed ground as well as opportunities for liesure and recreation uses.

However, if the overall environmental situation in Berlin is taken into account then perhaps the selected solution should adopt a more radical stance with an emphasis geared towards improving environmental conditions rather than simply maintaining the status quo. Given the high-density of development suggested by the winner of the first prize in the design competition for Alexanderplatz, it might be appropriate to consider an environmentally advantageous concept for Alexanderstrasse. In this case the type solution with a substantial green finger connecting the river and Alexanderplatz would be more appropriate since this would not only involve unsealing large areas of ground but also a reduction in the road network with a subsequent decrease in emmisions and an improvement in the micro-climate.

Within large scale reurbanisation projects the emphasis which is currently given to particular planning objectives should be carefully considered. In cities other than Berlin the issues will be similar. Contradictions among the objectives appears to be inevitable when the demands of the market (dense, accessible, interchangeable, short-term), social expectations (housing, employment, leisure), and environmental necessity (pollution, energy, micro-climate, water, natural resources) have to be considered as part of a development scenario. A further contradiction can appear through the differing planning levels. In the case of Berlin the city-wide objectives of a new city centre set against the local aims for the district Berlin-Mitte.

Solutions which offer a compromise between objectives with no additional environmental damage can be adopted as a panacea for all participants and interest groups involved in the development process, but at some point a consequent and consistent effort must be made to repair the existing environmental damage and for this proposals are required which offer a positive environmental balance. In this respect combinations of environmentally acceptable planning objectives and development proposals which seek in their spatial organisation, use patterns, circulation systems and building structure to improve the environment will form a crucial component in the effort to maintain urban quality. 